\title{
ANALISIS TINGKAT KEPUASAN MASYARAKAT TERHADAP KUALITAS PELAYANAN JASA RSUD DR. RASIDIN PADANG
}

\author{
ZUL HAZIZAH, FERRA YANUAR, RIRI LESTARI \\ Jurusan Matematika, \\ Fakultas Matematika dan Ilmu Pengetahuan Alam, Universitas Andalas, \\ Kampus UNAND Limau Manis Padang, Indonesia. \\ email : zulazizah2305@gmail.com
}

\begin{abstract}
Abstrak. Kualitas pelayanan yang baik dan kepuasan pasien merupakan salah satu tolak ukur dari perkembangan pelayanan suatu rumah sakit, penelitian ini bertujuan untuk menganalisa tingkat kepuasan pasien terhadap kualitas pelayanan jasa dengan metode Customer Satisfaction Index (CSI), Analisis Kesenjangan (Gap Analysis), Importance Performance Analysis (IPA) dan Bagan Kendali $T^{2}$ Hotelling. Data yang digunakan pada penelitian ini adalah data primer yang diperoleh dengan menyebarkan kuisioner kepada 125 pasien di RSUD Rasidin Padang. Penyebaran kuisioner dilakukan pada bulan Desember 2016. Kajian ini menghasilkan nilai CSI 85.78\%, hal ini berarti secara umum indeks kepuasan responden terhadap kualitas pelayanan berada dikriteria sangat puas. Berdasarkan analisis kesenjangan, kebanyakan responden memberikan penilaian terhadap kinerja pelayanan pada RSUD masih berada dibawah kepentingan dari semua indikator pelayanan yang ditanyakan. Berdasarkan metode IPA terdapat 10 indikator yang menjadi prioritas untuk diperbaiki. Berdasarkan Bagan Kendali $T^{2}$ Hotelling pada data kinerja dan kepentingan menunjukan output bagan kendali belum terkendali karena terdapat data yang out of control, sehingga dapat dikatakan persepsi responden terhadap kualitas pelayanan RSUD Dr. Rasidin Padang tidak seragam.

Kata Kunci: Customer Satisfaction Index (CSI), Analisis Kesenjangan (Gap Analysis), Kepuasan Responden, Importance Performance Analysis (IPA), Bagan Kendali $T^{2}$ Hotelling
\end{abstract}

\section{Pendahuluan}

Pelayanan kesehatan merupakan faktor penting dalam meningkatkan derajat kesehatan dan kesejahteraan masyarakat. RSUD Dr. Rasidin Padang, merupakan salah satu rumah sakit besar yang terletak di kota Padang, Provinsi Sumatera Barat, yang pengelolaannya dipegang oleh Pemerintah Kota Padang. Penentuan tingkat kepuasan pasien dapat dilakukan dengan menggunakan metode Customer Service Index (CSI). Ada indikator yang harus dipertahankan, indikator yang harus ditingkatkan kinerjanya dan ada indikator yang menjadi prioritas sehingga harus diperhatikan penuh oleh RSUD Dr. Rasidin Padang. Tingkat kesenjangan kualitas pelayanan antara tingkat kinerja dan tingkat kepentingan dapat dianalisis dengan analisis kesenjangan (Gap Analysis). Untuk mengukur beberapa indikator pengukuran kualitas jasa dan mengidentifikasi tindakan yang perlu dilakukan dapat digunakan metode Importance Performance Analysis (IPA) . Dalam metode ini 
diperlukan pengukuran tingkat kesesuaian terhadap beberapa indikator yang merujuk pada pelayanan jasa yang diberikan, hal ini bertujuan untuk mengetahui seberapa besar kepuasan responden terhadap kinerja perusahaan, dan seberapa besar pemahaman penyedia jasa mengetahui keinginan responden terhadap jasa yang diberikan. Selanjutnya Bagan Kendali $T^{2}$ Hotelling digunakan untuk mengetahui keragaman persepsi responden terhadap kualitas pelayanan jasa RSUD Dr. Rasidin Padang.

\section{Landasan Teori}

\subsection{Pelayanan dan Kualitas Pelayanan}

Kualitas pelayanan sangatlah penting untuk diperhatikan karena mempengaruhi minat masyarakat terhadap penggunaan jasa dari suatu instansi. Kualitas pelayanan merupakan suatu proses atau aktivitas yang dilakukan oleh perusahaan yang dapat dirasakan langsung hasilnya, yang pada akhirnya memenuhi harapan pengguna jasa. Berdasarkan Peraturan Menteri Birokrasi No 16 Tahun 2014 tentang pedoman survei kepuasan masyarakat terhadap penyelenggaraan pelayanan publik. Ruang lingkup survei kepuasan masyarakat dalam peraturan ini meliputi:

(1) Persyaratan.

(2) Prosedur.

(3) Waktu Pelayanan.

(4) Biaya/Tarif.

(5) Produkspesifikasi jenis pelayanan.

(6) Kompetensi pelaksana.

(7) Perilaku pelaksana.

(8) Maklumat Pelayanan.

(9) Penanganan Pengaduan saran dan masukan.

\subsection{Kuesioner}

Pada penelitian ini didesain sebuah koesioner yang berisikan semua indikator yang didefinisikan dalam Permenpan No. 16 Tahun 2014. kuesioner yang baik dapat diuji dengan uji validitas dan reliabilitas.

\subsubsection{Uji Validitas dan Reliabilitas Kuesioner}

Uji validitas adalah suatu alat ukuran yang menunjukan tingkat kevalidan atau sah suatu instrument, atau dengan kata lain sejauh mana ketepatan masing-masing pernyataan/pertanyaan pada kuesioner dalam mengukur variabel yang hendak diukur. Misalkan suatu peubah pada kuesioner diukur melalui $k$ atribut pernyataan. Validitas dari pernyataan ke-j, $j=1,2, \cdots, k$ diukur dengan membandingkan $r_{\text {hitung }}$ dengan $r_{\text {tabel }}$, dengan $r_{\text {hitung }}$ yang dapat dihitung menggunakan statistik uji dengan persamaan berikut:

$$
r_{\text {hitung }}=\frac{n \sum_{i=1}^{n} x_{i} y_{i}-\left(\sum_{i=1}^{n} x_{i j}\right)\left(\sum_{i=1}^{n} y_{i}\right)}{\sqrt{n \sum_{i=1}^{n} x_{i j}^{2}-\left(\sum_{i=1}^{n} x_{i j}\right)^{2}} \sqrt{n \sum_{i=1}^{n}} y_{i}^{2}-\left(n \sum_{i=1}^{n} y_{i}\right)^{2}},
$$


dimana

$$
\begin{aligned}
x_{i j} & : \text { skor item responden ke- } i \text { pada indikator } \mathrm{ke}-j, j=1,2, \cdots, k, \\
y_{i} & : \text { skor total responden } \mathrm{ke}-i, i=1,2, \cdots, n, \\
n: & \text { banyak responden. }
\end{aligned}
$$

Kemudian nilai statistik uji $r_{\text {hitung }}$ dibandingkan dengan nilai kritis $r_{((, n-2))}$ atau $r_{\text {tabel }}$. Pernyataan disimpulkan valid apabila $r_{\text {hitung }} \geq r_{\text {tabel }}[7]$.

Uji reliabilitas digunakan untuk mengukur apakah hasil pengukuran tersebut dapat dipercaya atau dihandalkan untuk digunakan dalam pengumpulan data. Uji reliabilitas pada penelitian ini menggunakan metode Alpha Cronbach $\left(C_{\alpha}\right)$, yang dirumuskan sebagai berikut

$$
C_{\alpha}=\left(\frac{k}{k-1}\right)\left(1-\frac{\sum_{j=1}^{k} s_{x j}^{2}}{s_{x^{2}}}\right),
$$

dimana:

$$
\begin{aligned}
k & \text { : banyaknya butir indikator, } \\
s_{y}^{2}: & \text { variansi skor total seluruh indikator, } \\
s_{x_{j}}^{2}: & \text { variansi skor indikator ke- } j \text {, dengan } j=1,2, \cdots, k .
\end{aligned}
$$

\subsection{Metode Analisis Data}

Pada tulisan ini dilakukan analisis data sebagai berikut.

\subsubsection{Customer Satisfaction Index (CSI)}

Customer Satisfaction Index (CSI) atau indek kepuasan pelanggan digunakan untuk menentukan tingkat kepuasan pelanggan secara menyeluruh dengan memperlihatkan tingkat kepentingan indikator-indikator jasa. Langkah-langkah yang dilakukan untuk menentukan Custumer Satisfaction Index (CSI) adalah sebagai berikut [1]:

(1) Menentukan Mean Importance Score (MIS), nilai ini berasal dari rata-rata tingkat kepentingan tiap indikator, dengan rumus:

$$
M I S_{j}=\frac{\sum_{i=1}^{n} y_{i j}}{n},
$$

dengan $y_{i j}$ merupakan skor kepentingan responden ke- $i$ indikator ke- $j$.

(2) Menentukan Mean Satisfaction Score (MSS) nilai ini berasal dari rata-rata tingkat kinerja tiap indikator, dengan rumus

$$
M S S_{j}=\frac{\sum_{i=1}^{n} x_{i j}}{n},
$$

dimana $x_{i j}$ merupakan skor kinerja responden ke- $i$ untuk indikator ke- $j$.

(3) Hitung Weight Factors (WF) hal merupakan persentasi nilai MIS per indikator terhadap total MIS seluruh indikator

$$
W F_{j}=\frac{M I S_{j}}{\sum_{i=1}^{k} M I S_{k}} \times 100 \%
$$


(4) Hitung Weight Score (WS) yang merupakan perkalian antara Weight Factor (WF) dengan rata-rata tingkat kepuasan Mean Satisfaction Score (MSS)

$$
W F_{j}=W F_{j} \times M S S_{j} .
$$

(5) Hitung Customer Satisfaction Index (CSI) dengan persamaan

$$
C S I=\frac{\sum_{i=1}^{k} W S_{j}}{H S} \times 100 \%,
$$

dimana Heigh Score (HS) merupakan skala maksimum yang digunakan dan $n$ merupakan banyak responden.

\subsubsection{Analisis Kesenjangan (Gap Analysis) Kualitas Pelayanan}

Gap Analysis merupakan metode pengukuran untuk mengetahui kesenjangan (gap) antara kinerja/persepsi dengan kepentingan yang dirasakan. Gap analysis ini juga bisa dinyatakan dalam persentase perbandingan antara kinerja dan kepentingan. Nilai persentase yang mendekati ke $100 \%$ menyatakan bahwa kinerja suatu pelayanan sudah sesuai harapan responden [2].

Langkah-langkah dalam menentukan Gap Analysis adalah sebagai berikut [1]:

(1) Menghitung rata-rata tingkat kinerja indikator ke- $j\left(\hat{x}_{j}\right)$ dengan persamaan:

$$
\hat{x}_{j}=\frac{\sum_{i=1}^{n} x_{i j}}{n} .
$$

(2) Menghitung rata-rata tingkat kepentingan indikator ke- $j\left(\hat{y}_{j}\right)$ dengan persamaan:

$$
\hat{y}_{j}=\frac{\sum_{i=1}^{n} y_{i j}}{n}
$$

(3) Menentukan selisih antara rata-rata tingkat kinerja indikator ke- $j\left(\hat{x}_{j}\right)$ dengan rata-rata tingkat kepentingan indikator ke- $j\left(\hat{y}_{j}\right)$ :

$$
\text { Gap }=\hat{x}_{j}-\hat{y}_{j}
$$

\subsubsection{Importance Performance Analysis (IPA)}

Analisis menggunakan metode IPA bertujuan untuk membandingkan tingkat kepentingan (importance) konsumen dengan kinerja (performance) menurut persepsi responden. Dalam metode IPA, langkah-langkah yang dilakukan untuk menentukan IPA adalah sebagai berikut :

(1) Menghitung rata-rata tingkat kepentingan indikator ke- $j\left(\hat{y}_{j}\right)$ dan tingkat kinerja indikator ke- $j\left(\hat{y}_{j}\right)$ dengan persamaan [10]:

$$
\begin{aligned}
& \hat{x}_{j}=\frac{\sum_{i=1}^{n} x_{i j}}{n}, \\
& \hat{y}_{j}=\frac{\sum_{i=1}^{n} y_{i j}}{n},
\end{aligned}
$$


dimana

$$
\begin{aligned}
\hat{x}_{j} & : \text { rata-rata skor kinerja indikator ke- } j, \\
\hat{y}_{j} & : \text { rata-rata skor kepentingan indikator ke- } j, \\
n & : \text { banyak responden. }
\end{aligned}
$$

(2) Menentukan dua garis yang berpotongan tegak lurus dengan cara menghitung rata-rata dari rata-rata tingkat kinerja $(\overline{\bar{x}})$ dan rata-rata dari rata-rata tingkat kepentingan $(\overline{\bar{y}})$ untuk keseluruhan indikator dengan persamaan [10]

$$
\begin{aligned}
& \overline{\bar{x}}_{j}=\frac{\sum_{j=1}^{k} \bar{x}_{j}}{k}, \\
& \overline{\bar{y}}_{j}=\frac{\sum_{j=1}^{k} \bar{y}_{j}}{k} .
\end{aligned}
$$

(3) Nilai tersebut $\left(\bar{x}_{j}, \bar{y}_{j}\right)$ diplotkan ke dalam diagram cartesius yang terbagi dalam empat kuadran setelah dipisah oleh garis $\overline{\bar{x}}$ dan $\overline{\bar{y}}$.

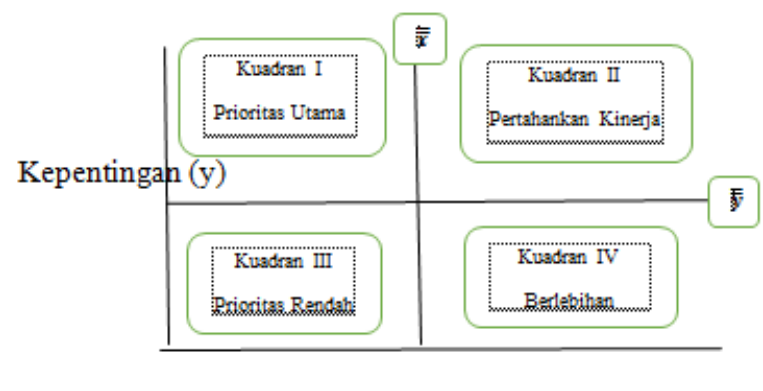

Kinerja (x)

Gambar 1. Pembagian Kuadran Metode (IPA)

\subsubsection{Bagan Kendali $T^{2}$ Hotelling}

Bagan kendali $T^{2}$ Hotelling merupakan jenis bagan kendali multivariat yang dapat mendeteksi adanya out of control (pengamatan berada diluar batas kendali) dan pergeseran proses dimana data bersifat multivariabel. Hal ini dikarenakan variabel yang lebih dari satu variabel dapat memperlihatkan hubungan korelasi antara variabel, maka dalam kasus tersebut lebih tepat kita gunakan bagan kendali $T^{2}$ Hotelling. Sebelum menghitung bagan kendali $T^{2}$ Hotelling, terlebih dahulu dihitung vektor rata-rata,

$$
\bar{x}=\left[\begin{array}{c}
\bar{x} 1 \\
\bar{x} 2 \\
\vdots \\
\bar{x}
\end{array}\right]
$$


dimana

$\bar{x}_{j}$ : nilai skor rata-rata karakteristik dimensi kinerja atau kepentingan indikator ke $-j$,

$\bar{x}_{i j}$ : nilai skor karakteristik dimensi kinerja atau kepentingan pengamatan ke-i indikator ke $-j$.

Selanjutnya dihitung varian kovarian setiap karakteristik kualitas dengan menggunakan persamaan $[7]$

$$
S=\frac{1}{n-1} \sum_{i=1}^{n}\left(x_{i}-\bar{x}\right)\left(x_{i}-\bar{x}\right)^{\prime},
$$

dimana

$\bar{x}$ : vektor rata-rata karakteristik dimensi kinerja atau kepentingan,

$S$ : matriks varian kovarian karakteristik dimensi kinerja atau kepentingan.

Setelah diperoleh perhitungan vektor rata-rata dan matriks varian kovarian, maka nilai $T^{2}$ Hotelling untuk pengamatan individu adalah [4]

$$
T_{i}^{2}=\left(x_{i}-\bar{x}\right)^{\prime} S^{-1}\left(x_{i}-\bar{x}\right), \text { untuk } i=1,2, \cdots, n,
$$

dimana

$T_{i}^{2}$ : nilai $T^{2}$ untuk setiap pengamatan ke $-i$,

$x_{i}$ : vektor skor karakteristik dimensi kinerja atau kepentingan ke $-i$,

$\bar{x}$ : vektor rata-rata karakteristik dimensi kinerja atau kepentingan

Batas kendali dari bagan kendali $T^{2}$ Hotelling untuk sampel berukuran besar, misalnya $n>100$, maka taksiran batas kendali adalah

$$
\begin{aligned}
& B K A=X_{\alpha, k}^{2}, \\
& B K B=0 .
\end{aligned}
$$

dengan $n$ merupakan jumlah sampel dan $k$ adalah jumlah karakteristik kualitas.

\section{Hasil dan Pembahasan}

Data yang digunakan pada penelitian ini adalah data primer yang diperoleh dengan menyebarkan kuisoner kepada 125 pasien di RSUD Dr. Rasidin Padang penyebaran kuisioner dilakukan pada bulan Desember 2016.

\subsection{Uji Validitas dan Uji Reliabilitas Kuisioner}

validitas dilakukan dengan cara membandingkan nilai $r_{\text {hitung }}$ dengan nilai $r_{\text {tabel }}$. Data ini menggunakan $d b=30-2=28$ dan taraf nyata yaitu $5 \%$ dengan $r_{\text {tabel }}=$ $r_{(\alpha, d b)},=r_{(0.05,28)}=0.374$. Berdasarkan hasil uji validitas setiap indikator untuk kinerja dan kepentingan dengan bantuan software SPSS menunjukan semua butir pernyataan indikator kinerja dan kepentingan dapat dikatakan memenuhi syarat validitas.

Dari perhitungan Alpha Cronbach dengan $k=32$, diperoleh nilai reliabilitas instrumen terhadap kinerja sebesar 0.853 , sedangkan nilai reliabilitas kepentingan 
sebesar 0.898, nilai Alpha Cronbach tersebut berada pada interval $0.80-1.00$. Hal ini berarti tolak $H_{0}$ sehingga pertanyaan setiap indikator reliabel. Dapat kita simpulkan bahwa tingkat reliabilitas kuisoner sangat kuat dalam mengukur data kinerja dan kepentingan RSUD Dr.Rasidin Padang.

\subsection{Customer Satisfaction Index (CSI)}

Berdasarkan hasil perhitungan diperoleh nilai CSI dengan $k=32$ pasien RSUD Dr.Rasidin sebesar 85,78 \%. Nilai ini terletak pada kisaran $0.81-1.00$, hal ini menjelaskan bahwa indeks kepuasan responden berada pada kriteria sangat puas, sehingga secara keseluruhan responden sudah merasa puas terhadap kinerja indikatorindikator yang terdapat pada RSUD Dr. Rasidin Padang.

\subsection{Analisis Kesenjangan (Gap Analysis) Kualitas Pelayanan}

Dari hasil perhitungan diatas dapat kita ketahui bahwa selisih antara tingkat kinerja dan kepentingan semuanya bernilai negatif. Hal ini berarti secara umum tingkat kinerja pelayanan RSUD. Dr. Rasidin Padang yang diwakili oleh 32 indikator belum sepenuhnya memenuhi harapan responden. Capaian tingkat kinerja pelayanan RSUD Dr. Rasidin Padang tertinggi adalah indikator kinerja petugas dalam memberikan hasil pelayanan diterima dengan benar, tepat dan sangat baik (E2) sebesar $96.73 \%$ dengan tingkat kesenjangan -0.24. Capaian tingkat kinerja pelayanan RSUD Dr. Rasidin Padang terendah adalah indikator aduan, saran dan masukan segera ditindaklanjuti oleh unit pelayanan ini (I2) sebesar 84.83\% dengan tingkat kesenjangan -0.632 .

\subsection{Importance Performance Analysis (IPA)}

Analisis kuadran berfungsi untuk menunjukan hubungan antara penilaian tingkat kepuasan responden dengan kepentingan. Setiap rata-rata indikator dijabarkan kedalam diagram cartesius berdasarkan penilaian performance (kinerja) dan importance (kepentingan). Sumbu $X$ adalah kinerja pelayanan dan sumbu $Y$ adalah kepentingan responden. Berikut penjelasan untuk Gambar 2.

(1) Kuadran I (Prioritas Utama).

Pada kuadran I (Prioritas Utama) setiap indikator-indikator dalam kuadran ini memiliki tingkat kepentingan yang tinggi menurut responden, namun kinerjanya masih rendah, sehingga indikator-indikator yang terdapat pada kuadran ini harus diprioritaskan untuk diperbaiki. Indikator yang termasuk dalam kuadran ini adalah Jenis dokumen yang dipersyaratkan untuk pengurusan di unit ini mudah untuk dilengkapi (A2), Informasi tentang prosedur pelayanan tersedia dengan lengkap dan jelas (B1), Lamanya proses pelayanan pada unit ini sudah sesuai dengan kepastian jadwal yang telah dijanjikan (C3), Biaya pelayanan di unit ini adalah wajar (D3), Petugas memberikan pelayanan dengan tepat dan cepat (G1), Petugas selalu bersedia membatu masyarakat tanpa diminta (G5), Petugas sabar dan bersedia menerima saran dan kritikan(G6), Petugas bersikap 


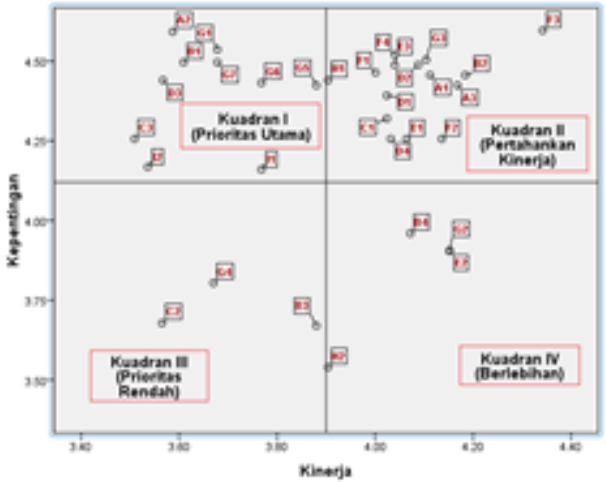

Gambar 2. Analisis Kuadran Importance Performance Analysis (IPA) Tingkat Kinerja dan Kepentingan Kualitas Pelayanan RSUD Dr. Rasidin Padang

ramah dalam memberikan pelayanan (G7), Unit ini menyediakan akses untuk masyarakat dalam menyalurkan aduan, saran dan masukan(I1), Aduan sasaran dan masukan segera ditindak lanjuti oleh unit ini(I2).

(2) Kuadran II (Pertahankan Kinerja).

Pada kuadran II (Pertahankan Kinerja) ini memilki memilki tingkat kepentingan yang tinggi dan kinerja juga dinilai baik oleh responden. Indikator-indikator yang terdapat pada kuadran ini merupakan kekuatan atau keunggulan RSUD Dr. Rasidin Padang.

(3) Kuadran III (Prioritas Rendah).

Pada kuadran III (Prioritas Rendah) memiliki tingkat kepentingan yang rendah dan kinerjanya dianggap kurang baik bagi responden. RSUD Dr. Rasidin perlu melakukan perbaikan kinerja terhadap indikator-indikator tersebut untuk mencegah indikator tersebut bergeser ke kuadran 1. Indikator-indikator yang termasuk dalam kuadran ini adalah Tata cara memberikan aduan, sara dan masukan tersedia dengan jelas (B3), Lama waktu pelayanan pada unit ini sudah wajar (C2), Petugas memberikan pelayanan yang adil tanpa membedabedakan masyarakat (G4).

(4) Kuadran IV (Berlebihan).

Indikator pada Kuadran IV (Berlebihan) memiliki tingkat kepentingan yang rendah menurut responden, namun memiliki kinerja yang baik sehingga dianggap berlebihan. Peningkatan kinerja pada indikator ini hanya akan menyebabkan pemborosan sumber daya.

\subsection{Bagan Kendali $T^{2}$ Hotelling}

Teknik analisis dengan analisis dengan data muktivariat terutama data variabel membutuhkan asumsi bahwa data mendekati ditribusi normal multivariat. sebelum membuat bagan kendali $T^{2}$ Hotelling asumsi yang harus dipenuhi terlebih dahulu 
adalah data observasi berdistribusi normal multivariat. Berdasarkan output hasil uji normalitas dimensi kinerja, diperoleh nilai $p_{\text {value }}>\alpha \geq \alpha$ dimana $0.119>0.05$. Hal ini berarti tolak $H_{0}$ yaitu data berdistribusi normal multivariat. Berdasarkan output hasil uji normalitas dimensi kepentingan, diperoleh nilai $p_{\text {value }}>\alpha$ dimana $0.613>0.05$. hal ini berarti tolak $H_{0}$ yaitu data berdistribusi normal multivariat.

\subsubsection{Bagan Kendali $T^{2}$ Hotelling untuk Dimensi Kinerja}

Dengan bantuan software, diperoleh output bagan kendali $T^{2}$ Hotelling sebagai berikut: Pengontrolan persepsi responden untuk dimensi kinerja dengan menggu-

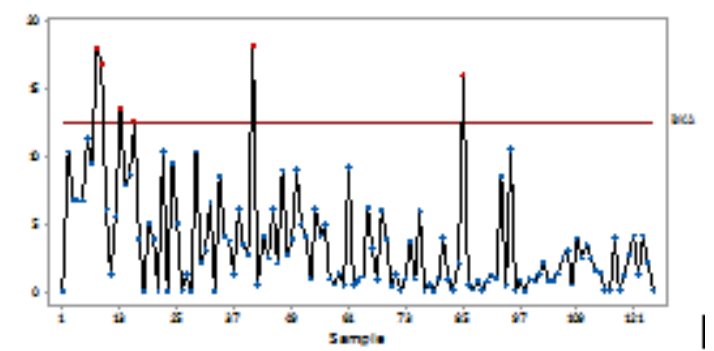

Gambar 3. Bagan Kendali $T^{2}$ Hotelling Dimensi Kinerja

nakan bagan kendali $T^{2}$ Hotelling mendeteksi semua pengamatan tidak ada yang berada di bawah Batas Kendali Bawah (BKB). Terdapat enam pengamatan yang berada diluar batas kendali (out of control), yaitu pengamatan ke 8,9,13,16,41 dan 85 dengan nilai $T^{2}$ Hotelling untuk enam pengamatan tersebut berada diatas Batas Kendali Atas (BKA). Hal ini berarti bahwa persepsi responden terkait kinerja pelayanan RSUD Dr. Rasidin Padang dari setiap indikator yang dinyatakan dalam kuesioner belum seragam namun tingkat kepuasan responden akan kinerja pelayanan sudah sangat baik. RSUD Dr. Rasidin Padang harus meningkatkan pelayanan agar kepuasan terhadap kinerja responden secara keseluruhan terpenuhi.

\subsubsection{Bagan Kendali $T^{2}$ Hotelling untuk Dimensi Kepentingan}

Dengan bantuan software diperoleh output bagan kendali $T^{2}$ Hotelling sebagai berikut: Pengontrolan persepsi responden untuk dimensi kepentingan dengan menggunakan bagan kendali $T^{2}$ Hotelling mendeteksi semua pengamatan tidak ada yang berada di bawah Batas Kendali Bawah (BKB). Terdapat lima pengamatan yang berada diluar batas kendali (out of control), yaitu pengamatan ke 9, 19, 34, 41 dan 50 dengan nilai $T^{2}$ Hotelling untuk lima pengamatan tersebut berada diatas Batas Kendali Atas (BKA). Hal ini berarti bahwa tingkat kepentingan responden terkait pelayanan RSUD Dr. Rasidin Padang dari setiap indikator yang dinyatakan dalam kuesioner belum seragam. 


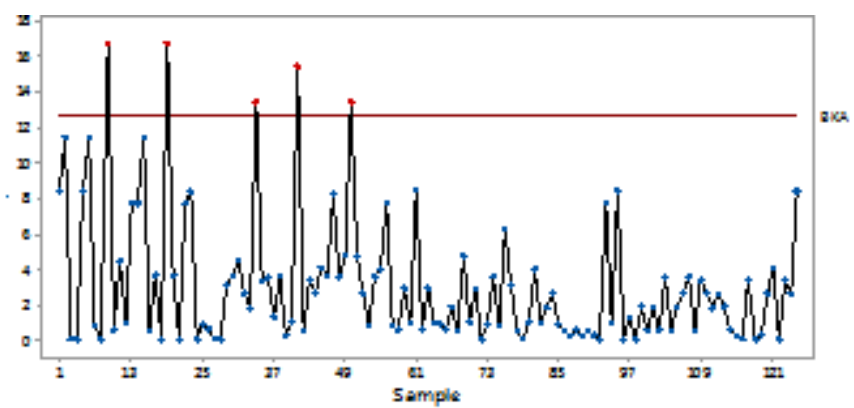

Gambar 4. Bagan Kendali $T^{2}$ Hotelling Dimensi Kepentingan

\section{Ucapan Terima kasih}

Penulis mengucapkan terima kasih kepada Bapak Dodi Devianto, Ibu Lyra Yulianti dan Bapak Zulakmal yang telah memberikan masukan dan saran sehingga makalah ini dapat diselesaikan dengan baik.

\section{Daftar Pustaka}

[1] Aritonang, R. L. 2005. Kepuasan Pelanggan. Jakarta: Gramedia

[2] Dahlquist, J. R. and Richard, J. R. 2012. Thecnical Analysis of Gaps. Publishing FT Press: New Jersey

[3] Johnson, R. A. and Wichern, D. W. 1998. Applied Multivate Statistical Analysis. Sixth Edition. Prentice-Hall International: New Jersey

[4] Montgomerry, D. C. 2009. Introduction to Statistical Quality Control, Four Edition. John Wiley and Son, Inc: New York

[5] Peraturan Menteri Pendayagunaan Aparatur Negara dan Reformasi birokrasi. 2014. Pedoman Survey Kepuasan Masyarakat tentang Pelayanan Publik

[6] Siegel, Sidney. 1985. Statistika Non Parametrik. PT. Gramedia: Jakarta

[7] Supranto, J. M. A. 1989. Statistik Teori dan Aplikasi. Edisi Kelima. Erlangga: Jakarta

[8] Supranto, J. M. A. 1989. Pengukuran Tingkat Kepuasan Pelanggan Untuk Menaikkan Pangsa Pasar. Rineka Cipta: Jakarta

[9] Tjiptono, Fandy. 1998. Manajemen Jasa. Andi Offset. Yogyakarta

[10] Walpole, R. E. 1995. Pengantar Statistika. Edisi Ketiga. Gramedia Pustaka Utama. Jakarta 